\title{
VARIAÇÕES DO MÉTODO DE QUANTIFICAÇÃO DA PROTEÍNA SOLÚVEL EM SOJA DESATIVADA UTILIZADA NA ALIMENTAÇÃO ANIMAL
}

\section{VARIATIONS OF THE METHOD OF QUANTIFICATION OF SOLUBLE PROTEIN IN DISACTIVATED SOY USED IN THE ANIMAL FEEDING}

\author{
Claudia Oliveira da Silveira ${ }^{1,2}$; Claucia Fernanda Volken de Souza ${ }^{3}$ \\ ${ }^{1}$ Centro Universitário - Univates - Lajeado - Brasil cau.silveira@gmail.com \\ ${ }^{2}$ Eleva Alimentos S/A - Arroio do Meio - Brasil \\ ${ }^{3}$ Centro Universitário - Univates - Lajeado - Brasil clauciavolken@,bol.com.br
}

\begin{abstract}
Resumo
Para que a soja possa ser utilizada na elaboração de rações animais esta é submetida a um tratamento térmico, a fim de eliminar os fatores antinutricionais. O método de solubilidade protéica é utilizado pelas indústrias produtoras de ração para determinar se a soja processada pode ser ou não utilizada na alimentação animal. Porém, esta análise apresenta, nas diferentes etapas de sua execução, variáveis que podem interferir na exatidão dos seus resultados, tais como granulometria da soja, velocidade de rotação da centrífuga e tempo de centrifugação. Portanto, o objetivo desse trabalho foi avaliar os efeitos do tempo de tostagem da soja, da granulometria de moagem do grão tostado e dos principais parâmetros do método de solubilidade protéica (velocidade de agitação para hidrólise, rotação e tempo de centrifugação) sobre o grau de solubilidade protéica. Os grãos de soja foram submetidos a três diferentes tempos de tostagem: 10; 12,5 e 15 minutos. Posteriormente, foram moídas em peneiras com orifícios de 0,5; 0,75 e 1,0 mm e submetidas às análises de proteína bruta, atividade ureática e solubilidade protéica. Os resultados de solubilidade protéica variaram de 80,62\% a 96,52\% demonstrando que há influência dos parâmetros estudados sobre o resultado analítico e quanto maior a granulometria da amostra menor é o resultado de solubilidade protéica. Além disso, constatou-se que ao aumentar o tempo de tostagem do grão de soja e a velocidade de agitação da amostra, durante a hidrólise, maior será o valor da proteína solúvel em decorrência do aumento da disponibilidade da matéria protéica.
\end{abstract}

Palavras-chave: soja grão desativada; alimentação animal; solubilidade protéica.

\section{Introdução}

A soja, vegetal com elevado teor protéico e energético, é uma das mais importantes culturas agrícolas brasileiras (GUEDES, 2007).

Com o desenvolvimento dos produtos protéicos oriundos da soja para a alimentação humana, nutricionistas perceberam que estes poderiam ser uma alternativa protéica importante para vários tipos de rações (BELLAVER, 1998). Aliado a isso, a restrição do uso de fontes protéicas de origem animal em rações pelo mercado internacional e, em menor grau, pelo mercado interno, geraram uma 
demanda extra de soja para a formulação das rações (MENDES, 2004). De acordo com Sindirações (2007), no Brasil são produzidos cerca de 48 milhões de toneladas de rações. Porém, segundo Soares (2004), não existem estimativas sobre o volume de soja integral utilizada pela indústria de ração, pois o grão in natura ou integral não é utilizado como ingrediente nas rações comerciais.

Segundo Mendes et al. (2004), o grão de soja é composto por, aproximadamente, 17 a 18\% de óleo e 35 a 37\% de proteína bruta de elevado valor biológico, com composição em aminoácidos essenciais favorável à alimentação de aves e suínos, mas deficiente em metionina e treonina. Além disso, a soja possui diversos fatores antinutricionais, tais como: inibidores da tripsina e quimiotripsina, lectinas, lipase e lipoxigenase, fatores alérgicos (glicinina e beta-conglicinina) e os polissacarídeos não amiláceos solúveis (BELLAVER, 1998). Devido à presença de tais fatores, que atuam negativamente sobre o desempenho animal, inibindo e interferindo na absorção de nutrientes, a soja in natura não deve ser utilizada na alimentação de monogástricos. Utiliza-se então o tratamento térmico para desativar tais compostos, provocando ainda a ruptura da parede celular do grão, liberando a proteína enclausurada, o que resulta no aumento do aproveitamento protéico (MENDES, 2004).

O controle de qualidade da soja integral processada (desativada) fornece informações sobre a inativação dos fatores antinutricionais e os efeitos do aquecimento sobre a qualidade da proteína. $\mathrm{O}$ subaquecimento mantém os fatores antinutricionais, ao passo que o superaquecimento causa redução da digestibilidade dos aminoácidos (MENDES, 2004). A solubilidade protéica é reconhecida como sendo um dos melhores métodos para avaliar sub ou superprocessamento (BELLAVER, 1998) e indica o percentual de proteína disponível para absorção pelo animal. O método envolve a determinação da solubilidade com solução de $\mathrm{KOH} \mathrm{0,2 \% .} \mathrm{O} \mathrm{princípio} \mathrm{do} \mathrm{mesmo}$ está baseado na reação de diferentes grupos amino livres entre si para formar pontes peptídicas, que reduzem a solubilidade da proteína (WARD, 1996). Segundo Mendes et al. (2004), a faixa ideal de variação da solubilidade para a alimentação animal é de 73 a 85\%. Já, segundo a ANFAR (2005), as sojas empregadas na alimentação animal devem apresentar um mínimo de $80 \%$ de solubilidade protéica. Valores abaixo de $70 \%$ indicam superaquecimento e acima de $85 \%$ relacionam-se à soja subprocessada (MENDES, 2004). Uma solubilidade protéica próxima a 100\% indica uma soja crua sem processamento (RUNHO, 2001).

A metodologia da solubilidade apresenta, nas diferentes etapas de sua execução, variáveis que podem interferir na exatidão dos seus resultados, tais como granulometria da soja, velocidade de rotação da centrífuga e tempo de centrifugação.

Portanto, o objetivo deste trabalho foi verificar o efeito do tempo de tostagem da soja e dos principais parâmetros do método de solubilidade de proteína, descrito pela ANFAR (2005), tais como velocidade de agitação para hidrólise, rotação e tempo de centrifugação e granulometria da 
soja desativada, sobre o resultado de solubilidade protéica, utilizando a metodologia de planejamento experimental e análise de superfície de resposta.

\section{Materiais e Métodos}

\subsection{Matéria-prima}

As sojas desativadas foram elaboradas com soja (Glycine max (L) Merril) safra 2007.

\subsection{Preparo da soja desativada}

Os grãos de soja foram submetidos a três diferentes tempos de tostagem (variável $x_{1}$ do planejamento experimental), 10; 12,5 e 15 minutos para desativação, em digestor com capacidade de 5 toneladas.

As amostras de soja tostadas foram moídas em peneiras com orifício de 0,5 $\mathrm{mm} ; 0,75 \mathrm{~mm}$ e 1,0 $\mathrm{mm}$ (variável $x_{5}$ do planejamento experimental), em moinho refrigerado Marconi, tipo rotor modelo MA 090-CFT a $5900 \mathrm{rpm}$.

As amostras foram processadas e analisadas na Fábrica de Rações Eleva S.A., em Arroio do Meio.

\subsection{Análises químicas}

Todas as amostras foram submetidas às análises de proteína bruta, pelo método Kjedahl, solubilidade protéica e atividade ureática (potenciometria), conforme metodologias descritas pela ANFAR (2005).

Foram pesadas 2 gramas das amostras com diferentes tempos de tostagem e granulometria e submetidas aos seguintes parâmetros analíticos da análise de solubilidade protéica em $\mathrm{KOH} 0,2 \%$ : velocidade de agitação para hidrólise de 590, 780 e $1170 \mathrm{rpm}$ (variável $x_{2}$ do planejamento experimental), velocidade de centrifugação de 1500, 2750 e $4000 \mathrm{rpm}$ (variável $x_{3}$ do planejamento experimental) e tempo de centrifugação de 4, 7 e 10 minutos (variável $x_{4}$ do planejamento experimental). Posteriormente foram digeridas e destiladas conforme descrição da análise de proteína bruta.

Todas as análises foram realizadas em duplicata. 


\subsection{Análise estatística}

Com o objetivo de avaliar os efeitos do tempo de tostagem da soja, da granulometria de moagem do grão tostado e dos principais parâmetros do método de solubilidade protéica (velocidade de agitação para hidrólise, rotação e tempo de centrifugação) sobre o grau de solubilidade protéica foram delineados experimentos através do planejamento fatorial e análise de superfície de resposta. A otimização consistiu de um planejamento fatorial $2^{5}$, incluindo três pontos centrais, resultando num total de 35 experimentos. As variáveis foram estudadas em 3 níveis. Em todos os ensaios foram determinados os valores de solubilidade protéica. O planejamento experimental e a análise dos resultados foram realizados com o auxílio do software STATISTICA versão 7.0 .

\section{Resultados e Discussão}

Na tabela 1 são apresentados os resultados de caracterização físico-química da soja crua e do grão tostado durante 10;12,5 e 15 minutos. Os valores de solubilidade protéica e atividade ureática variaram como esperado após tratamento térmico, indicando inativação dos fatores antinutricionais, conforme relatado por Brum (2006).

Tabela 1 - Caracterização físico-química de sementes de soja crua, após tratamento térmico (desativação) e índices preconizados pela ANFAR (2005).

\begin{tabular}{lcccccc}
\hline & \multicolumn{6}{c}{ Produto } \\
\cline { 2 - 7 } \multicolumn{1}{c}{ Análise } & Soja crua & $\begin{array}{c}\text { Índices } \\
\text { ANFAR }\end{array}$ & $\begin{array}{c}\text { Soja } \\
\text { desativada } \\
10 \text { min }\end{array}$ & $\begin{array}{c}\text { Soja } \\
\text { desativada } \\
12,5 \text { min }\end{array}$ & $\begin{array}{c}\text { Soja } \\
\text { desativada } \\
15 \text { min }\end{array}$ & $\begin{array}{c}\text { Índices } \\
\text { ANFAR }\end{array}$ \\
\hline Proteína Bruta $(\%)$ & 35,0 & 36 & 35,0 & 35,0 & 35,0 & 36 \\
Atividade Ureática $(\Delta \mathrm{pH})$ & 2,2 & - & 0,20 & 0,16 & 0,09 & $<0,2$ \\
Solubilidade em $\mathrm{KOH}(\%)$ & 99,9 & - & 92,6 & 83,2 & 85,0 & $>80$ \\
\hline
\end{tabular}

A tabela 2 apresenta a matriz do planejamento experimental com a identificação dos níveis (codificados e reais) das variáveis e as respectivas respostas de solubilidade protéica.

Conforme as condições de tempo de tostagem, velocidade de agitação, rotação e tempo de centrifugação e granulometria da soja tostada, os resultados de solubilidade protéica variaram de 80,62 a 96,52 \%, demonstrando que as diferentes variáveis estudadas influenciam no resultado analítico de solubilidade protéica. 
Considerando um tempo de tostagem constante, quanto maior a granulometria da amostra mais baixo serão os resultados da solubilidade protéica, estando diretamente relacionado à velocidade de agitação e a velocidade de rotação da centrífuga.

Tabela 2 - Planejamento experimental com as combinações das variáveis, codificadas e reais, e respectivas respostas de solubilidade protéica.

\begin{tabular}{|c|c|c|c|c|c|c|c|c|c|c|c|}
\hline \multirow[t]{2}{*}{ Tratamento } & \multicolumn{5}{|c|}{ Variáveis Codificada } & \multicolumn{5}{|c|}{ Variáveis Reais } & \multirow{2}{*}{$\begin{array}{l}\text { Solubilidade } \\
\text { Protéica (\%) }\end{array}$} \\
\hline & $x_{1}$ & $x_{2}$ & $x_{3}$ & $x_{4}$ & $x_{5}$ & $X_{1}$ & $X_{2}$ & $X_{3}$ & $X_{4}$ & $X_{5}$ & \\
\hline 1 & -1 & -1 & -1 & -1 & -1 & 10 & 390 & 1500 & 4 & 0,50 & 90,68 \\
\hline 2 & -1 & -1 & -1 & -1 & +1 & 10 & 390 & 1500 & 4 & 1,00 & 89,06 \\
\hline 3 & -1 & -1 & -1 & +1 & -1 & 10 & 390 & 1500 & 10 & 0,50 & 92,51 \\
\hline 4 & -1 & -1 & -1 & +1 & +1 & 10 & 390 & 1500 & 10 & 1,00 & 83,64 \\
\hline 5 & -1 & -1 & +1 & -1 & -1 & 10 & 390 & 4000 & 4 & 0,50 & 90,22 \\
\hline 6 & -1 & -1 & +1 & -1 & +1 & 10 & 390 & 4000 & 4 & 1,00 & 83,16 \\
\hline 7 & -1 & -1 & +1 & +1 & -1 & 10 & 390 & 4000 & 10 & 0,50 & 90,73 \\
\hline 8 & -1 & -1 & +1 & +1 & +1 & 10 & 390 & 4000 & 10 & 1,00 & 86,42 \\
\hline 9 & -1 & +1 & -1 & -1 & -1 & 10 & 1170 & 1500 & 4 & 0,50 & 92,55 \\
\hline 10 & -1 & +1 & -1 & -1 & +1 & 10 & 1170 & 1500 & 4 & 1,00 & 84,12 \\
\hline 11 & -1 & +1 & -1 & +1 & -1 & 10 & 1170 & 1500 & 10 & 0,50 & 90,71 \\
\hline 12 & -1 & +1 & -1 & +1 & +1 & 10 & 1170 & 1500 & 10 & 1,00 & 81,80 \\
\hline 13 & -1 & +1 & +1 & -1 & -1 & 10 & 1170 & 4000 & 4 & 0,50 & 89,83 \\
\hline 14 & -1 & +1 & +1 & -1 & +1 & 10 & 1170 & 4000 & 4 & 1,00 & 83,73 \\
\hline 15 & -1 & +1 & +1 & +1 & -1 & 10 & 1170 & 4000 & 10 & 0,50 & 91,63 \\
\hline 16 & -1 & +1 & +1 & +1 & +1 & 10 & 1170 & 4000 & 10 & 1,00 & 85,58 \\
\hline 17 & +1 & -1 & -1 & -1 & -1 & 15 & 390 & 1500 & 4 & 0,50 & 90,87 \\
\hline 18 & +1 & -1 & -1 & -1 & +1 & 15 & 390 & 1500 & 4 & 1,00 & 83,52 \\
\hline 19 & +1 & -1 & -1 & +1 & -1 & 15 & 390 & 1500 & 10 & 0,50 & 93,70 \\
\hline 20 & +1 & -1 & -1 & +1 & +1 & 15 & 390 & 1500 & 10 & 1,00 & 82,55 \\
\hline 21 & +1 & -1 & +1 & -1 & -1 & 15 & 390 & 4000 & 4 & 0,50 & 89,93 \\
\hline 22 & +1 & -1 & +1 & -1 & +1 & 15 & 390 & 4000 & 4 & 1,00 & 82,55 \\
\hline 23 & +1 & -1 & +1 & +1 & -1 & 15 & 390 & 4000 & 10 & 0,50 & 89,93 \\
\hline 24 & +1 & -1 & +1 & +1 & +1 & 15 & 390 & 4000 & 10 & 1,00 & 80,62 \\
\hline 25 & +1 & +1 & -1 & -1 & -1 & 15 & 1170 & 1500 & 4 & 0,50 & 94,47 \\
\hline 26 & +1 & +1 & -1 & -1 & +1 & 15 & 1170 & 1500 & 4 & 1,00 & 86,42 \\
\hline 27 & +1 & +1 & -1 & +1 & -1 & 15 & 1170 & 1500 & 10 & 0,50 & 96,52 \\
\hline 28 & +1 & +1 & -1 & +1 & +1 & 15 & 1170 & 1500 & 10 & 1,00 & 85,45 \\
\hline 29 & +1 & +1 & +1 & -1 & -1 & 15 & 1170 & 4000 & 4 & 0,50 & 90,73 \\
\hline 30 & +1 & +1 & +1 & -1 & +1 & 15 & 1170 & 4000 & 4 & 1,00 & 92,80 \\
\hline 31 & +1 & +1 & +1 & +1 & -1 & 15 & 1170 & 4000 & 10 & 0,50 & 89,65 \\
\hline 32 & +1 & +1 & +1 & +1 & +1 & 15 & 1170 & 4000 & 10 & 1,00 & 85,63 \\
\hline 33 & 0 & 0 & 0 & 0 & 0 & 12,5 & 780 & 2750 & 7 & 0,75 & 83,24 \\
\hline 34 & 0 & 0 & 0 & 0 & 0 & 12,5 & 780 & 2750 & 7 & 0,75 & 83,24 \\
\hline 35 & 0 & 0 & 0 & 0 & 0 & 12,5 & 780 & 2750 & 7 & 0,75 & 83,24 \\
\hline
\end{tabular}

Os resultados são a média de 2 experimentos.

$x_{1}, x_{2}, x_{3}, x_{4}$ e $x_{5}$ são os valores codificados.

$X_{1}, X_{2}, X_{3}, X_{4}$ e $X_{5}$ são os valores reais.

$X_{1}=$ tempo de tostagem $(\min ) ; X_{2}=$ velocidade de agitação $(\mathrm{rpm}) ; X_{3}=$ rotação da centrífuga $(\mathrm{rpm}) ; X_{4}=$ tempo de centrifugação (min); $X_{5}=$ granulometria (mm).

A significância de cada coeficiente da regressão foi determinada pelo valor-t e $P$, os quais estão apresentados na Tabela 3. 
Tabela 3 - Efeitos estimados para solubilidade protéica.

\begin{tabular}{lccc}
\hline $\begin{array}{l}\text { Variáveis } \\
\text { independentes }\end{array}$ & Efeito & Valor-t & $\begin{array}{c}\text { Significância } \\
\text { (Valor-P) }\end{array}$ \\
\cline { 2 - 4 } Intercepto & 87,7548 & 182,9341 & $<0,0001$ \\
$x_{1}$ & 0,56077 & 0,5589 & 0,5828 \\
$x_{2}$ & 1,34725 & 1,3427 & 0,1952 \\
$x_{3}$ & $-0,96495$ & $-0,9617$ & 0,3483 \\
$x_{4}$ & $-0,47259$ & $-0,4710$ & 0,6430 \\
$x_{5}{ }^{*}$ & $-6,72447$ & $-6,7018$ & $<0,0001$ \\
$x_{1} \cdot x_{2}$ & 2,15388 & 2,1466 & 0,0449 \\
$x_{1} \cdot x_{3}$ & $-0,49141$ & $-0,4898$ & 0,6299 \\
$x_{1} \cdot x_{4}$ & $-0,43244$ & $-0,4310$ & 0,6713 \\
$x_{1} \cdot x_{5}$ & $-0,30695$ & $-0,3059$ & 0,7630 \\
$x_{2} \cdot x_{3}$ & 0,65587 & 0,6537 & 0,5212 \\
$x_{2} \cdot x_{4}$ & $-0,48775$ & $-0,4861$ & 0,6325 \\
$x_{2} \cdot x_{5}$ & 0,40463 & 0,4033 & 0,6913 \\
$x_{3} \cdot x_{4}$ & 0,1288 & 0,1284 & 0,8992 \\
$x_{3} \cdot x_{5}$ & 1,45519 & 1,4503 & 0,1633 \\
$x_{4} \cdot x_{5}$ & $-1,23544$ & $-1,2313$ & 0,2332 \\
\hline
\end{tabular}

* Estatisticamente significativo a $99 \%$ de confiança.

* Estatisticamente significativo a 95\% de confiança.

$x_{1}=$ tempo de tostagem $(\mathrm{min}) ; x_{2}=$ velocidade de agitação $(\mathrm{rpm}) ; x_{3}=$ rotação da centrífuga $(\mathrm{rpm}) ; x_{4}=$ tempo de centrifugação (min); $x_{5}=$ granulometria $(\mathrm{mm})$.

$\mathrm{O}$ efeito linear negativo da granulometria com o valor de $\mathrm{P} x_{5}<0,0001$, é o mais significativo. Este resultado indica que a solubilidade protéica diminui com o aumento da granulometria. A granulometria a que a amostra é preparada para análise é o aspecto mais crítico no método, afetando diretamente no grau de solubilidade protéica e, portanto, na confiabilidade do resultado analítico. Isso ocorre, pois à medida que se aumenta a superfície de contato dos grânulos, facilita-se a extração da fração nitrogenada da amostra solúvel em $\mathrm{KOH}$ 0,2\%.

O efeito linear positivo da interação entre as variáveis tempo de tostagem e velocidade de agitação da amostra para hidrólise, com um valor de $\mathrm{P} x_{1} \cdot x_{2}<0,0449$ indica que estes fatores associados também são importantes para a exatidão analítica do método de solubilidade protéica. Este resultado indica que quanto mais tempo a soja permanecer no reator e mais rápida for a agitação na etapa de hidrólise maior será o resultado da análise de solubilidade protéica.

Dentro do possível, o modelo foi simplificado pela eliminação dos termos estatisticamente não significativos. Porém os termos do efeito linear da velocidade de agitação $\left(\mathrm{P} x_{2}<0,1952\right)$, velocidade da rotação da centrífuga $\left(\mathrm{P} x_{3}<0,3483\right)$ e interação rotação da centrífuga-granulometria $\left(\mathrm{P} x_{3} \cdot x_{5}<0,1633\right)$ e tempo de centrifugação-granulometria $\left(\mathrm{P} x_{4} \cdot x_{5}<0,2332\right)$ foram mantidos no modelo tendo em vista as suas magnitudes. O modelo codificado de primeira ordem, que relaciona o resultado da análise de solubilidade protéica em função do tempo de tostagem, velocidade de 
agitação, rotação e tempo de centrifugação e ainda granulometria da amostra, é apresentada na equação 1:

$$
Y=87,7548+0,6736 x_{2}-0,4825 x_{3}-3,3622 x_{5}+1,0769 x_{1} \cdot x_{2}+0,72769 x_{3} \cdot x_{5}-0,6177 x_{4} \cdot x_{5}
$$

Onde: $Y$ é a resposta predita pelo modelo para a solubilidade protéica (\%), $x_{1}$ é o tempo de tostagem ( $\mathrm{min}), x_{2}$ é a velocidade de agitação (rpm), $x_{3}$ é a rotação da centrífuga (rpm), $x_{4}$ é o tempo de centrifugação ( $\mathrm{min})$ e $x_{5}$ é a granulometria $(\mathrm{mm})$, como variáveis codificadas.

A análise de variância (ANOVA) foi empregada para a determinação da significância do modelo polinominal de primeira ordem. O modelo foi significativo ( $p<0,000089$ ), sendo o coeficiente de determinação igual a 0,75 . Portanto, o modelo, como expressado na equação 1 , descreve adequadamente a resposta do resultado analítico de solubilidade protéica, nas condições avaliadas.

Então, é possível construir as superfícies de contorno, relacionando a solubilidade protéica com as variáveis, tempo de tostagem, velocidade de agitação, rotação da centrífuga, tempo de centrifugação e granulometria. As Figuras 1 a 5 apresentam as superfícies de contorno para o efeito: granulometria x velocidade de agitação (Figura 1), granulometria x rotação da centrífuga (Figura 2), granulometria x tempo de centrifugação (Figura 3), velocidade de agitação x tempo de tostagem (Figura 4) e granulometria $\mathrm{x}$ tempo de tostagem (Figura 5), na solubilidade protéica.

Figura 1 - Superfície de contato para o efeito granulometria x velocidade de agitação

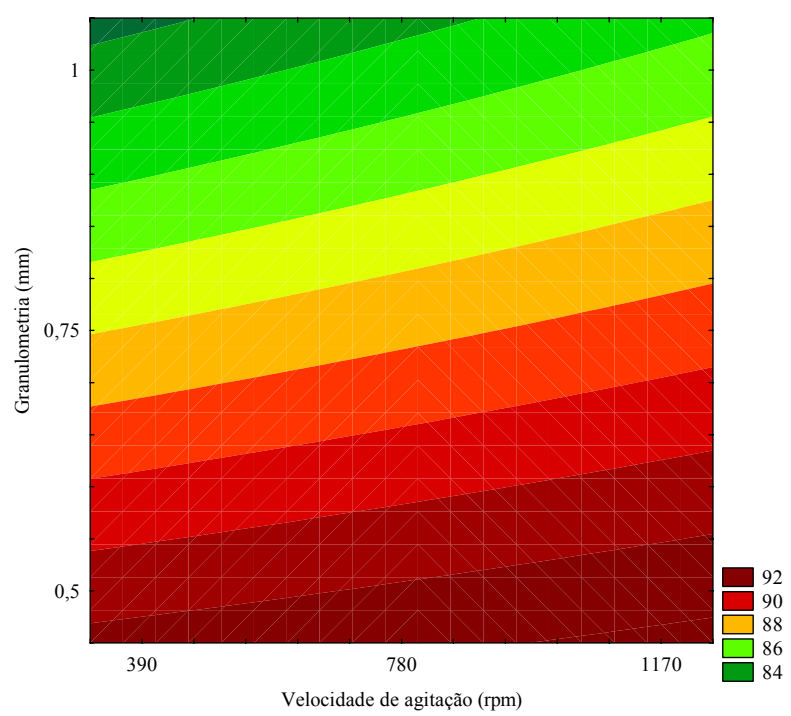


Figura 2 - Superfície de contorno para o efeito granulometria x rotação da centrífuga

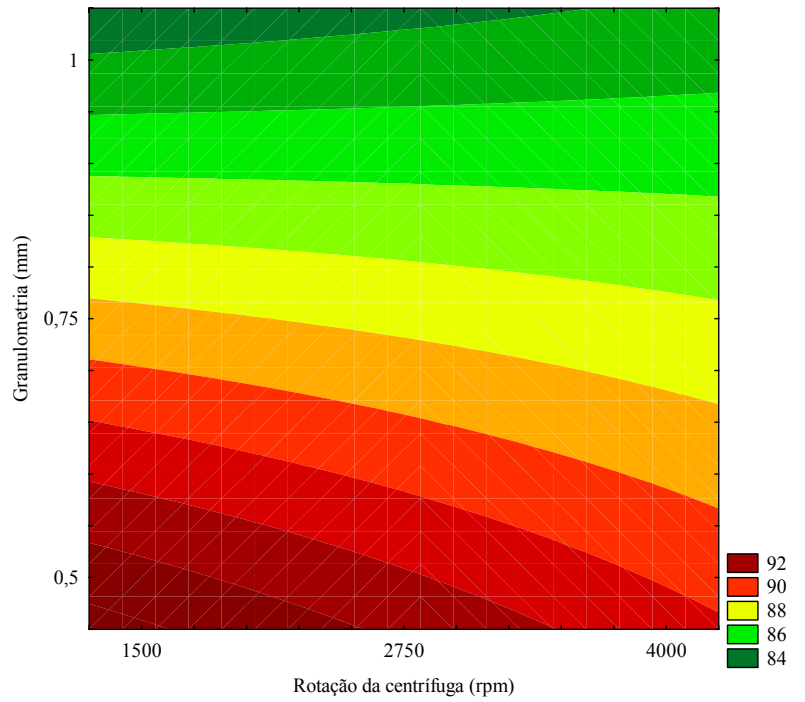

Figura 3 - Superfície de contorno para o efeito granulometria x tempo de centrifugação

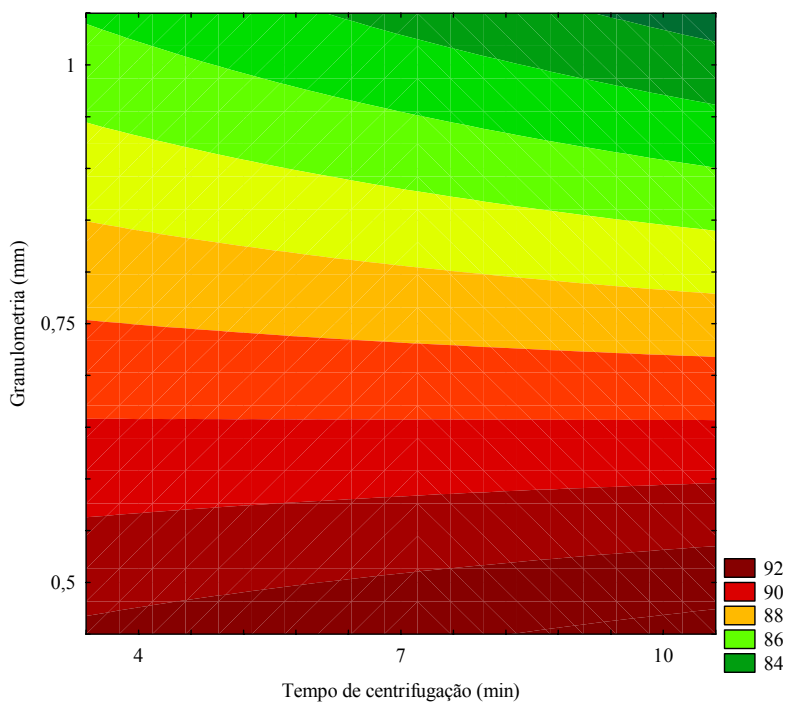

Figura 4 - Superfície de contorno para o efeito velocidade de agitação x rotação de tostagem

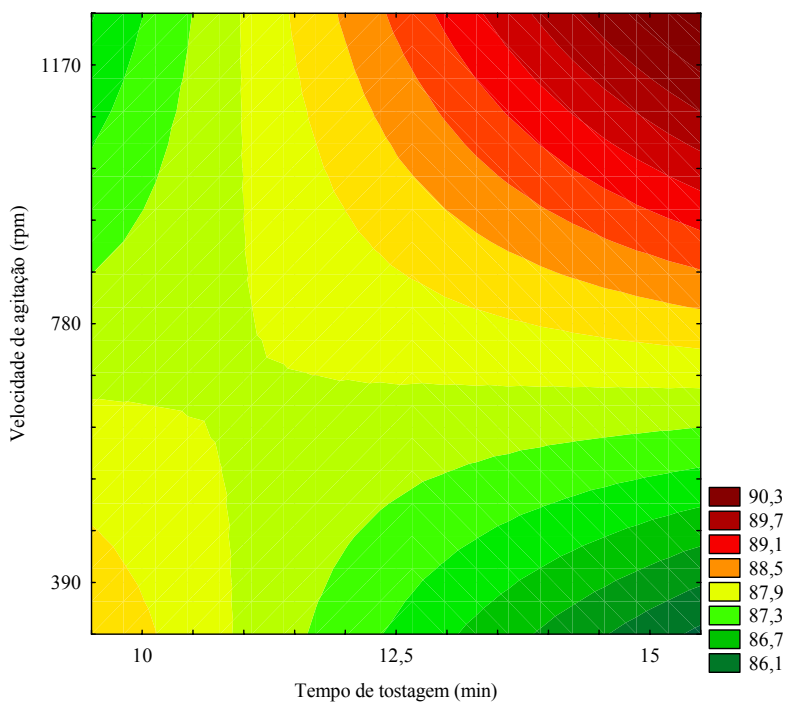


Figura 5 - Superfície de contorno para o efeito granulometria $\mathrm{x}$ tempo de tostagem

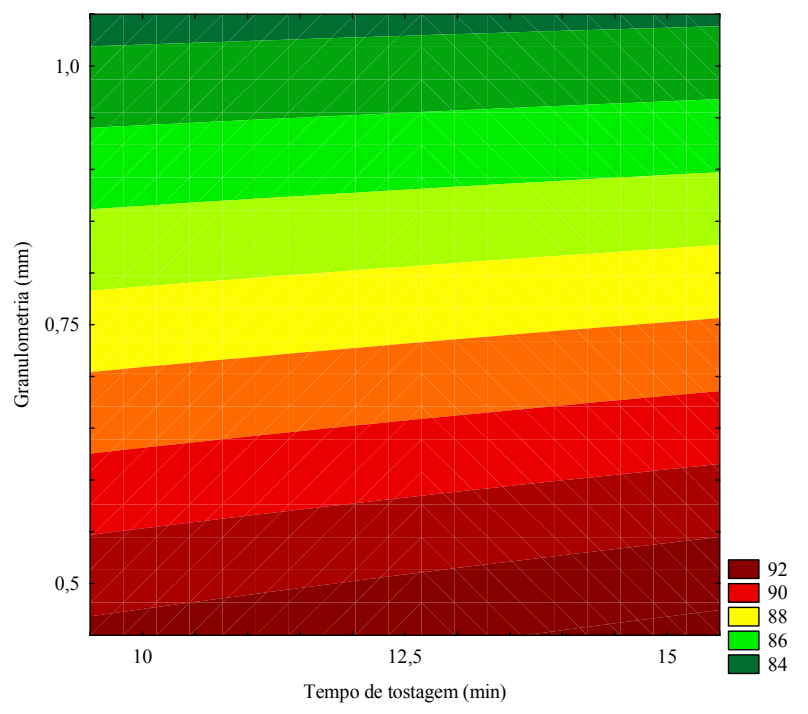

Analisando as superfícies de contorno podemos verificar a existência de uma região com solubilidade entre $89-95 \%$, considerada adequada às exigências nutricionais das rações animais, para cada uma das variáveis estudadas: tempo de tostagem, $15 \mathrm{~min}$; moagem com peneira, 0,5 mm; velocidade de agitação, 1170 rpm e velocidade de centrifugação de 1500 rpm durante 4 minutos.

\title{
4. Conclusão
}

Neste trabalho os efeitos do tempo de tostagem da soja, da granulometria do grão desativado e dos principais parâmetros da metodologia de solubilidade protéica foram estudados, a fim de encontrar as variáveis que influenciam no teor de proteína solúvel e dessa forma aumentar a confiabilidade do método que qualifica a soja desativada, através da análise de solubilidade protéica em $\mathrm{KOH} 0,2 \%$. Entre as variáveis estudadas verificou-se que quanto maior a granulometria da amostra menor será o resultado encontrado, podendo representar um falso erro no processo. Determinou-se ainda que, conforme aumenta o tempo de tostagem e a velocidade de agitação da amostra durante a hidrólise, maior é o valor de proteína solúvel, em decorrência do aumento da disponibilidade da matéria protéica. Portanto, o controle da granulometria da soja desativada, que será submetida à análise de solubilidade, e da velocidade de agitação para hidrólise são fundamentais para que haja uma padronização nos resultados de solubilidade protéica.

\begin{abstract}
So that the soy can be used in the elaboration of animal food this is submitted to a thermal treatment, in order to eliminate the anti-nutricional factors. The method of protein solubility is used by the producing industries of ration to determine if the processed soy can or cannot be used in the animal feeding. However, this analysis presents, in the different stages of its execution, variable that can interfere in the accuracy of the results, such as grinding a of the soy, speed of rotation of the
\end{abstract}


centrifugal machine and time of centrifugation. Therefore, the aim of this work was to evaluate the effect of the time of toasted of the soy, of the ginding of milling of the toast grain and the main parameters of the method of protein solubility (speed of agitation for hydrolysis, rotation and time of centrifugation) on the degree of protein solubility. The soy grains had been submitted to the three different times of toasting: 10; 12.5 and 15 minutes. Later they had been worn out in bolter with orifices of $0.5 ; 0.75$ and $1.0 \mathrm{~mm}$ and submitted to the rough protein analysis, urea activity and protein solubility. The results of proteín soluble varied from $80.62 \%$ to $96.52 \%$ showing that there is influence of the parameters studied on analytical result and the bigger the grinding sample, the lower sample is the protein solubility result. Moreover, this is evidence that while increasing the time of toasting of the soy grain and the speed of agitation of the sample, during hydrolysis, greater will be the value of the soluble protein in result of the increase of the availability of the protein substance.

Word-keys: disactivated soy grain; animal feeding; protein solubility.

\section{Referências}

ANFAR. Compêndio Brasileiro de Alimentação Animal - Métodos Analíticos, 204p, 2005.

BELLAVER, C. (1998). Processamento da soja e suas implicações na alimentação de suínos e aves, disponível em $<$ www.cnpsa.embrapa.br>, acesso em 20/07/2007.

BRUM, P. A. R.; et al. Características nutricionais da soja desativada por diferentes processos térmicos para alimentação de frangos de corte. Comunicado Técnico: Embrapa, n.451,p.1-5, 2006.

GUEDES, J. V. C; ; et al. Ácaros associados à cultura de soja no Rio Grande do Sul. Rev. Neotropical Entomology, n.36, p.288-293, 2007.

MENDES, W. S., et al. Composição química e valor nutritivo da soja crua e submetida a diferentes processamentos térmicos para suínos em crescimento. Arq. Bras. Med. Vet. Zootec, n.56, p.207-213, 2004.

RUNHO, R. C. (2001). Farelo de soja: processamento e qualidade. Poli-nutri Alimentos, Artigos Técnicos, disponível em $<$ www.polinutri.com.br $>$, acesso em 20/07/2007.

SINDIRAÇÕES. Controle de qualidade em fábricas de ração, (6/6/2007). Sindirações: Portal da Alimentação animal, disponível em < $<$ www.sindirações.org.br>, acesso em 20/07/2007.

SOARES JR, M. S. Substituição do farelo de soja por soja integral em rações extrusadas para aqüicultura. Pesquisa Agrop. Tropical, n.34, p.29-37, 2004.

WARD, N.E. Quality considerations for soybean meal. American Soybean Association. Blairstown, NJ, 195/11/95, v.1, 1996.

\section{Inserir aqui dados completos de todos os autores:}

Nome completo: Claudia Oliveira da Silveira

Filiação institucional: Eleva Alimentos S/A

Departamento: Laboratório Bromatológico

Função ou cargo ocupado: Supervisora da Qualidade

Endereço completo para correspondência (bairro, cidade, estado, país e CEP): Rua Presidente Vargas, 777. Aimoré. Arroio do Meio. RS. Brasil. CEP 95940-000

Telefones para contato: (51) 84037719, (51) 37169250

e-mail: cau.silveira@gmail.com 
Nome completo: Claucia Fernanda Volken de Souza

Filiação institucional: Centro Universitário - UNIVATES

Departamento: CETEC

Função ou cargo ocupado: professora assistente

Endereço completo para correspondência (bairro, cidade, estado, país e CEP): Rua Senador Salgado Filho, 257/404. Centro. Esteio. RS. Brasil. CEP 93260-140.

Telefones para contato: (51)99490016, (51)34592469

e-mail:clauciavolken@ig.com.br ou clauciavolken@bol.com.br 